\title{
PHÌNH TIỂU NHĨ TRÁI KHỔNG LỔ BẨM SINH
}

\section{Phạm Quốc Đạt*, Dương Đức Hùng*, Trưong Thanh Hương*, Lê Thanh Tùng*}

\section{I. ĐẠTT VẤN ĐỀ}

Phình tiểu nhĩ trái (giant left atrial appendage aneurysm) hay nhĩ trái có thể do nguyên nhân bẩm sinh hoặc mắc phải. Các trường hợp phình nhĩ trái và tiểu nhĩ trái mắc phải thường do nguyên nhân thứ phát như bệnh van hai lá hoặc rối loạn chức năng thất trái [1]. Phình nhĩ trái haytiểu nhĩ trái bẩm sinh khá hiếm gặp, và thường gặp ở tiểu nhĩ trái nhiều hơn [2]. Nguyên nhân được cho là bất thường bẩm sinh của lớp cơ của tiểu nhĩ trái [1].

Chúng tôi báo cáo một trường hợp lâm sàng phình tiểu nhĩ trái khổng lồ với biểu hiện rối loạn nhịp đã được phẫu thuật cắt bỏ tiểu nhĩ, sau mổ bệnh nhân về nhịp xoang và hết triệu chứng lâm sàng.

\section{CA LÂM SÀNG}

Bệnh nhân nam 16 tuổi, vào viện với triệu chứng hồi hộp, trống ngực. Khám lâm sàng, tim không có tiếng thổi. Điện tâm đồ có hình ảnh nhịp nhanh trên thất, xen kẽ là rung nhĩ cơn trên nền nhịp xoang (hình 1). X-Quang tim phổi có hình ảnh lồi cung tiểu nhĩ trái (hình 2). Siêu âm tim qua thành ngực có một khối lớn nằm cạnh nhĩ trái, kích thước $97 \times 67 \mathrm{~mm}$, bên trong có cuộn âm và thông với nhĩ trái. Các buồng tim không giãn, chức năng hai thất bình thường, không tăng áp lực động mạch phổi. Chẩn đoán phình tiểu nhĩ trái được khẳng định trên siêu âm thực quản (hình 3). Chụp cộng hưởng từ có hình ảnh tổn thương dạng khối cạnh thất trái, thông với nhĩ trái, bờ đều. Trên xung cine có tổn thương dạng cuộn bên trong và dòng phụt vào nhĩ trái. Chụp cắt lớp vi tính 256 dãy, túi phình tiểu nhĩ trái kích thước 97x77x114mm, đậm độ thuốc không đều, ngấm thuốc trong thì muộn, thành mỏng không thấy huyết khối.Túi phình chèn ép vào thất trái, đẩy tim sang phải và tĩnh mạch phổi phải xuống dưới. Các mạch vành xuất phát bình thường, không hẹp tắc. Động mạch mũ chạy ở chân của tiểu nhĩ trái giống như giải phẫu bình thường (hình 4). Chẩn đoán trước mổ: phình tiểu nhĩ trái khổng lồ, rối loạn nhịp tim.

Bệnh nhân được phẫu thuật qua đường dọc giữa xương ức, thiết lập máy tuần hoàn ngoài cơ thể. Tổn thương trong mổ thấy tiểu nhĩ trái phình khổng lồ (hình 5) đè ép vào các cấu trúc xung quanh, hệ thống mạch vành bình thường, van hai lá cấu trúc bình thường, không có huyết khối trong tiểu nhĩ trái cũng như trong buồng tim. Tiến hành cắt toàn bộ tiểu nhĩ trái đến sát chân, khâu đóng chân tiểu nhĩ trái hai lớp. Tiểu nhĩ cắt ra có thành rất mỏng, mặt trong khá nhẵn, không có huyết khối (hình 5). Thả cặp động mạch chủ, tim đập lại nhịp xoang. Bệnh nhân rút nội khí quản sau $12 \mathrm{~h}$, không có biến chứng gì. Điện tâm đồ ngay sau mổ có nhịp xoang (hình 6). Bệnh nhân ra viện sau 1 tuần, triệu chứng lâm sàng bình thường.

* Đơn vị phẫu thuật Tim mạch C8, Viện Tim mạch, Bệnh viện Bach Mai

Ngườ chịu trách nhiệm khoa học: TS. Dưong Đức Hùng Ngày nhận bài: 01/08/2017 - Ngày Cho Phép Đăng: 07/08/2017 Phản Biện Khoa học: PGS.TS. Đặng Ngọc Hùng GS.TS. Lê Ngọc Thành 

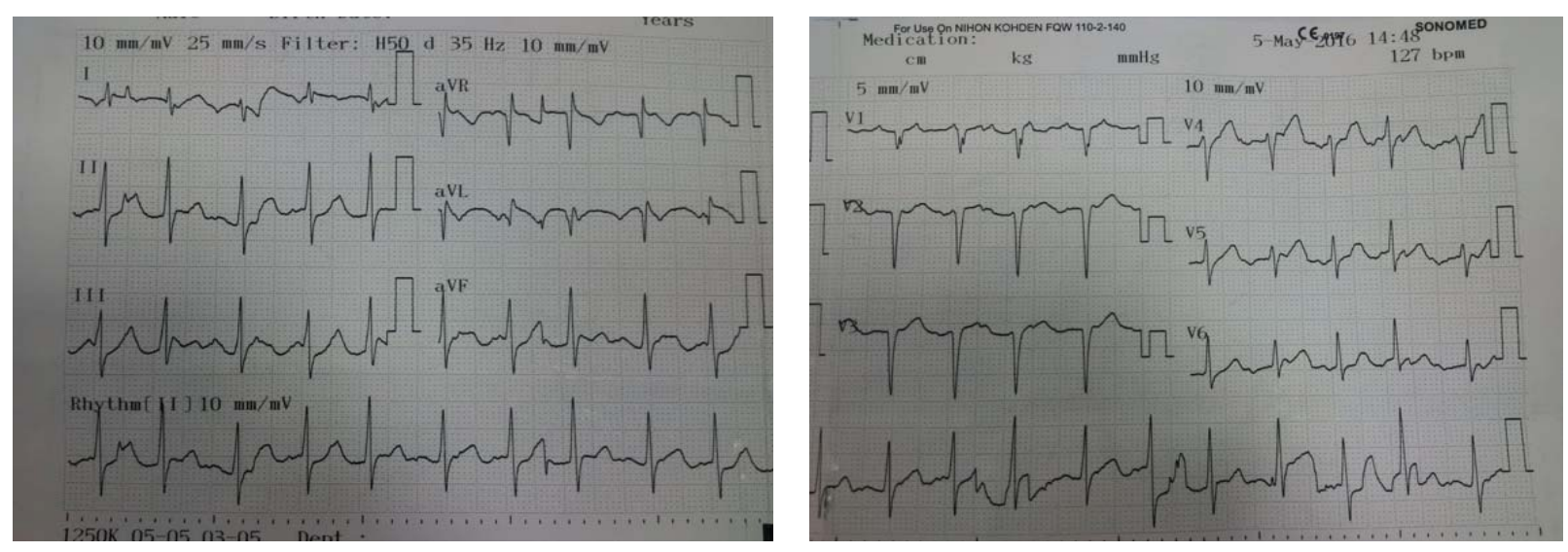

Hình 1. Điện tâm đồ truớc phẫu thuật

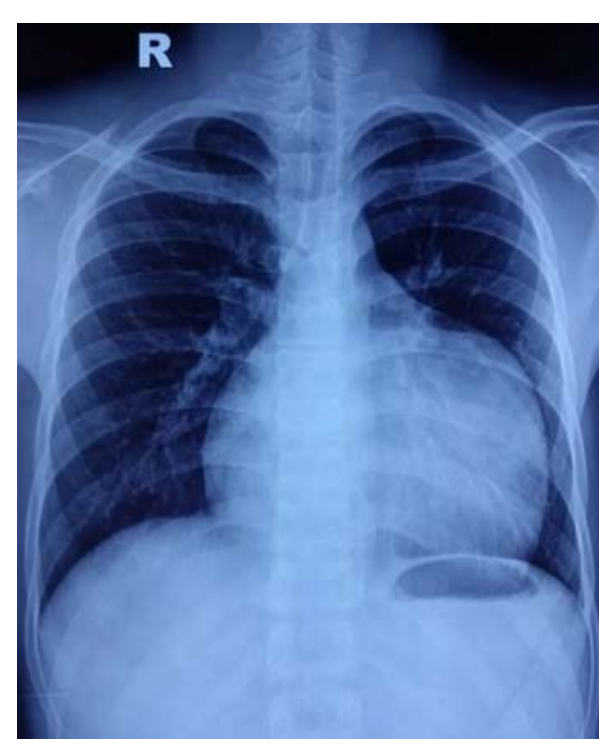

Hình 2. X Quang tim phổi, phồng cung tiểu nhĩ trái
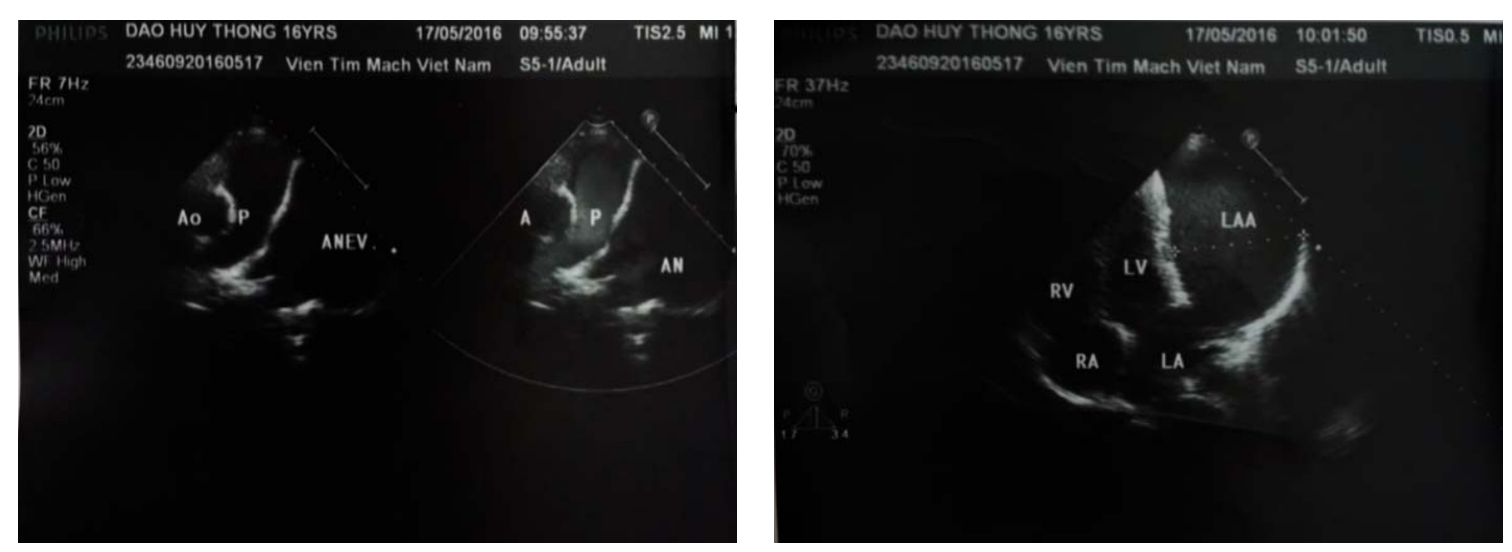

Hình 3. Siêu âm qua thành ngục và qua thực quản 

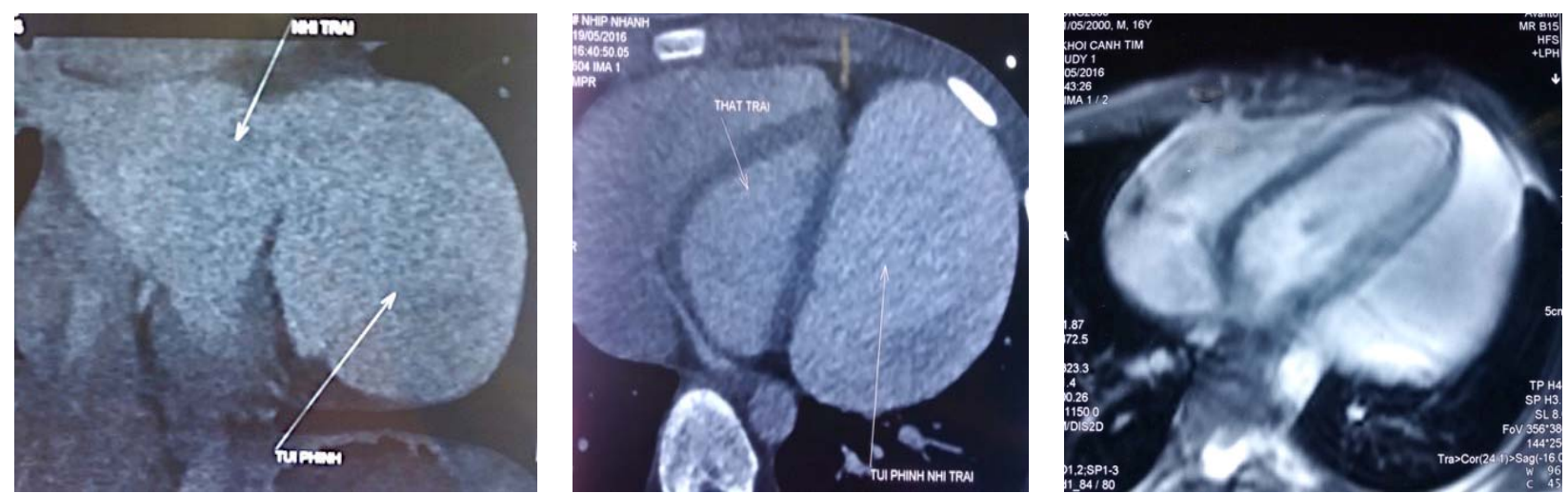

Hình 4. Cộng hưởng tù và cắt lớp vi tính đa dãy
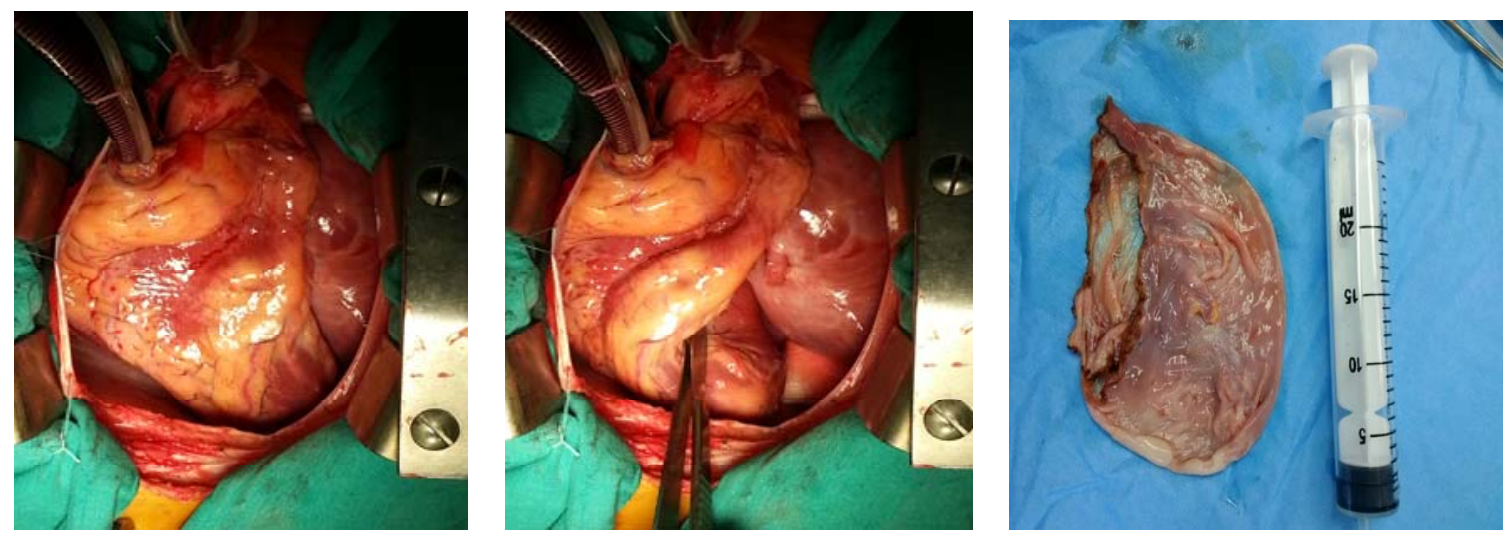

Hìn 5. Hình ảnh tổn thwơng trong mổ

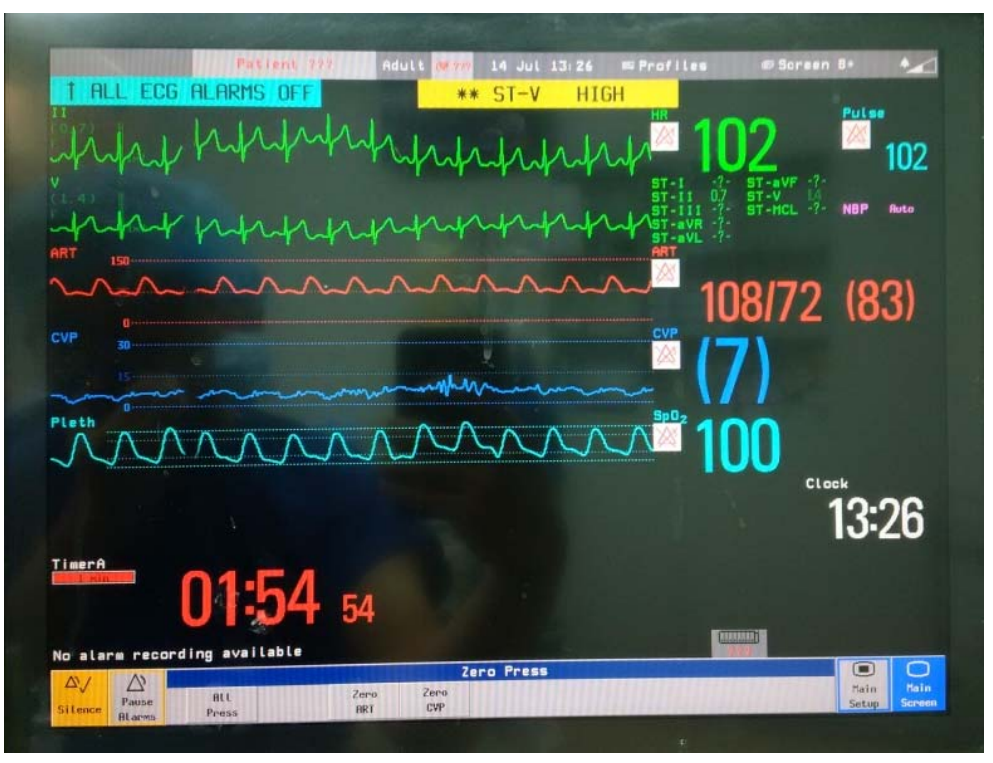

Hình 6. Điện tâm đồ sau mổ 


\section{THẢO LUẬN}

Phình tiểu nhĩ trái đơn độc rất hiếm gặp trên lâm sàng, thường được chẩn đoán trong khoảng từ 20-40 tuổi [2],[3]. Có rất ít báo cáo phình tiểu nhĩ trái phát hiện ở trẻ em [4]. Chẩn đoán phình tiểu nhĩ trái có nhiều phương pháp, từ siêu âm qua thành ngực, thực quản đến chụp cộng hưởng từ hay cắt lớp vi tính đa dãy. Điểm quan trọng là phải xác định vị trí của khối phình so với mạch vành, tĩnh mạch phổi và các cấu trúc khác của tim. Xác định có huyết khối trong buồng tim không? có bệnh mạch vành kèm theo không, đặc biệt trên bệnh nhân cao tuổi [5]. Chẩn đoán phân biệt thường bao gồm: $u$ trung thất, nang màng tim, u tim, dịch màng tim khu trú [1],[2].

Hậu quả của phình tiểu nhĩ trái thường gây nên rối loạn nhịp do những ổ phát xung động bất thường; và có thể dẫn đến hình thành huyết khối do dòng máu chảy chậm, gây tắc mạch hệ [1]. Do những biến chứng trên, chẩn đoán sớm và phẫu thuật cắt bỏ tiểu nhĩ trái là phương pháp điều trị cơ bản, thậm chí ở những bệnh nhân chưa có triệu chứng lâm sàng $[1,2]$. Mở đường dọc giữa xương ức, cắt bỏ tiểu nhĩ trái dưới sự trợ giúp của máy tuần hoàn ngoài cơ thể là phương pháp tiếp cận an toàn, đặc biệt trong các trường hợp dễ xuất hiện rối loạn nhịp mất huyết động hay các trường hợp tiểu nhĩ trái có huyết khối và cổ rộng. Bệnh nhân của chúng tôi được lựa chọn phương pháp trên và cho kết quả tốt sau mổ.

\section{KẾT LUẬN}

Tóm lại, phình tiểu nhĩ trái bẩm sinh là bệnh lý hiếm gặp, hậu quả gây ra rối loạn nhịp tim và tắc mạch do huyết khối, vì vậy chẩn đoán sớm và phẫu thuật cắt tiểu nhĩ là biện pháp an toàn và cho kết quả tốt.

\section{TÀI LIỆU THAM KHẢO}

1. Yao R, Hunsaker RP, Gelman B. An unusual echocardiogram. J Cardiothorac Vasc Anesth 2008;22:636-8.

2. Foale RA, Gibson TC, Guyer DE, Gillam L, King ME, Weyman AE. Congenital aneurysms of the left atrium: recognition by cross-sectional echocardiography. Circulation 1982;66:1065-9.

3. Thadani U, Whitaker W, Watson DA. Congenital intrapericardial aneurysms of the left atrium. Thorax 1975;30:102-9.

4. Awasthy N, Tomar M, Radhakrishnan S, Shrivastava S, Iyer KS. Symptomatic giant left atrial aneurysmina child: a rare entity.Images PaediatrCardiol 2010;12:9-13. 5. Vagefi PA, Choudhry M, Hilgenberg AD. Excision of an aneurysm of the left atrial appendage. J Thorac Cardiovasc Surg 2007;133:822-3. 